\title{
https://doi.org/10.46813/2021-136-117 \\ MODELING OF OSCILLATORY AND ROTARY TRAJECTORIES OF ELECTRONS IN GRADIENT MAGNETIC FIELD MAGNETRON GUN
}

\author{
A.S. Mazmanishvili, N.G. Reshetnyak \\ National Science Center “Kharkov Institute of Physics and Technology”, Kharkiv, Ukraine \\ E-mail: mazmanishvili@gmail.com
}

\begin{abstract}
The motion of electrons in cylindrical magnetic field with variable strength along the axis is considered. The formation of a beam with energy of $55 \mathrm{keV}$ in the longitudinal direction during its transport in solenoidal magnetic field with large gradient has been studied. The bifurcation regimes of the dynamics of particles during their movement along the transport axis both forward to the target and back to the cathode region are considered. The operating modes of the gun are obtained, in which the particle experiences the "bottleneck" effect and returns to the cathode region. It is shown that for given electron energy and fixed magnetic field, the parameter that determines the reflection of the particle is the polar angle of entry with respect to the axis of the cylindrical magnetic field. The results of numerical simulation on the motion of the electron flow are presented.
\end{abstract}

PACS: 29.27.Fh

\section{FORMULATION OF THE PROBLEM}

Magnetron guns with cold secondary-emission cathodes are promising for their use in the creation of powerful microwave devices, in accelerator technology due to the high current density, constructive simplicity, stability of cathode emission, etc. [1]. As an object of research, the magnetron gun has the advantage that it can be modified for carrying out experiments of various types [2]. The use of intense magnetic fields with an increased gradient of their intensity makes it possible to consider new phenomena in the spatial picture of the evolution of electron beams. Despite the complexity of the analytical study [3], to obtain quantitative dependencies, it is quite possible to use computational methods and compare numerical results with experimental data. The object of this work is the study of the parameters of the electron beam during its transportation in the intense gradient magnetic field of the solenoid and the construction of a computational model of the motion of the electron flow in the region of the field growth. The aim of the study was to create a mathematical model of the motion of an electron beam with an energy of tens of $\mathrm{keV}$ in a gradient magnetic field, to study the formation of the trajectories of the beam electrons from the initial conditions and the distribution of the magnetic field along the axis of the system.

Earlier, in the course of numerical experiments [4], the effect of the reverse motion of electrons in a gradient magnetic field of magnetron gun was discovered. In this work, on the basis of the Hamiltonian formalism of the motion of electrons in a magnetic field, a software tool was synthesized [5], which makes it possible to numerically simulate the dynamics of tubular electron flows in decreasing magnetic field of the solenoid. The results of numerical modeling on the motion of the electron flow are presented. The obtained simulation results show that it is possible to experimentally establish the phenomenon of reverse motion.

\section{MATHEMATICAL MODEL}

To construct mathematical model of the solution, we will use the axial symmetry of the problem. In the polar coordinate system $(r, z, \vartheta)$, we use the Hamiltonian of an electron in the magnetic field in a cylindrical coordinate system [6]

$$
H=\frac{p_{r}^{2}+p_{z}^{2}}{2 m}+\frac{1}{2 m}\left(\frac{p_{\vartheta}}{r}-e_{0} A\right)^{2},
$$

and the equations of motion following from it for coordinates and momenta have the general form

$$
\left\{\begin{array}{c}
\dot{r}=\frac{p_{r}}{m}, \\
\dot{z}=\frac{p_{z}}{m}, \\
\dot{\vartheta}=\frac{1}{m}\left(\frac{p_{\vartheta}}{r}-e_{0} B r f(z)\right) \frac{1}{r}, \\
\dot{p}_{r}=\frac{1}{m}\left(\frac{p_{\vartheta}}{r}-e_{0} B r f(z)\right)\left(\frac{p_{\vartheta}}{r^{2}}+e_{0} B f(z)\right), \\
\dot{p}_{z}=\frac{1}{m}\left(\frac{p_{\vartheta}}{r}-e_{0} B r f(z)\right)\left(e_{0} B r \frac{\partial}{\partial z} f(z)\right), \\
\dot{p}_{\vartheta}=0 .
\end{array}\right.
$$

Here, $e_{0}, m$ are the charge and rest mass of the electron, $p_{r}, p_{z}, p_{\vartheta}$ are the canonical impulses, $A$ is the magnetic potential. Taking into account the azimuthal symmetry, we will now write it in the form $A(r, z)=\operatorname{Brf}(z)$, where $f(z)$ is the function of the longitudinal coordinate, which we will dispose of below, $B$ is the magnetic field strength at the point under consideration.

In the reduced system (2) of 6 equations, we pass, using the speed of light $c$, from the current time $t$ to the variable $S=c t$ (it is proportional to the path that the particle has traveled along the trajectory), the derivative along it will be denoted by a prime. For canonical impulses, we will replace $p_{r}=e_{0} B q_{r}, \quad p_{z}=e_{0} B q_{z}$, $p_{\vartheta}=e_{0} B q_{\vartheta}$. After transformations, we arrive at the system of equations

$$
\left\{\begin{array}{c}
r^{\prime}=\mu q_{r}, \\
z^{\prime}=\mu q_{z}, \\
\vartheta^{\prime}=\mu\left(q_{\vartheta} / r^{2}-f(z)\right), \\
q_{r}^{\prime}=\mu r\left(q_{\vartheta} / r^{2}-f(z)\right)\left(q_{\vartheta} / r^{2}+f(z)\right), \\
q_{z}^{\prime}=\mu r^{2}\left(q_{\vartheta} / r^{2}-f(z)\right) d f(z) / d z, \\
q_{\vartheta}^{\prime}=0 .
\end{array}\right.
$$


In equations (3) $\mu=e_{0} B / m c$. We choose the amplitude $B$ so that it is possible to use the function $B f(z)$ over the entire range of possible values $z$. Equations (3) must be supplemented with the initial conditions $r_{0}, z_{0}$, $\vartheta_{0}$ and also $q_{r 0}, q_{z 0}, q_{\vartheta 0}$. From the computational point of view, the problem can be formulated as the problem of finding a solution to a system of ordinary differential equations with fixed initial conditions on a given interval. The formulated Cauchy problem can be solved, provided that it is possible at each step of integration of equations (3) to use functions $f(z)$ and $d f(z) / d z$ as analytical functions. This made it possible to obtain solutions of system (2) in the form of 6-dimensional arrays describing trajectories.

\section{MAGNETIC FIELD}

In [6], the operation of a magnetron gun was previously described. An essential factor influencing its operation is the form of the used solenoidal magnetic field (Figs. 1 and 2), which has cylindrical symmetry. This makes it possible to use the system of equations (3) for analysis and numerical modeling.

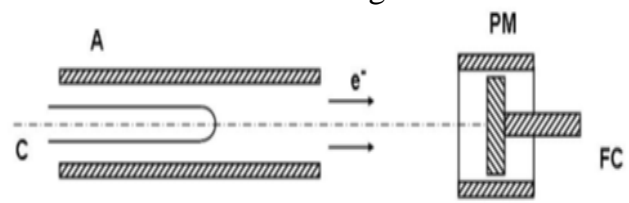

Fig. 1. Scheme of beam movement, A - anode; $\mathrm{C}$ - cathode; $\mathrm{PM}$ - permanent magnet; $\mathrm{FC}$ - target

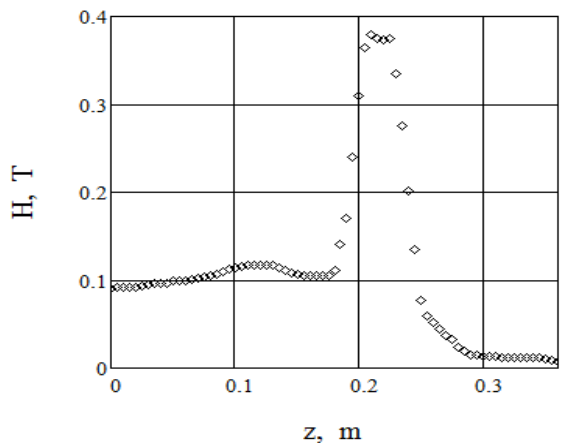

Fig. 2. Experimental data of the magnetic field $H$

A software tool based on an analytical model of the magnetic field distribution along the axis of an ideal solenoid has been developed. This made it possible, based on the data on the transportation axis (see Fig. 2), to reconstruct the magnetic field amplitude $f(z)$ and its derivative $d f(z) / d z$ as analytical functions of the longitudinal coordinate $z$ (Fig. 3).

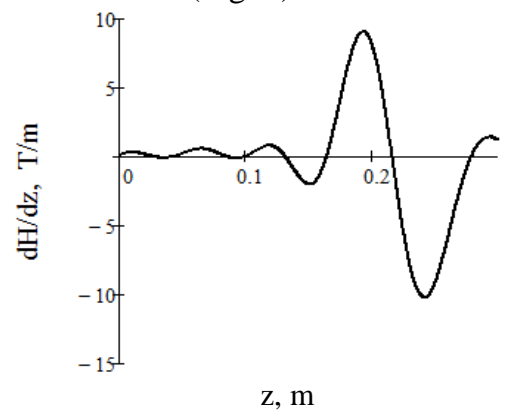

Fig. 3. Approximation of the derivative $d \mathrm{H} / d z$ magnetic field

\section{NUMERICAL SIMULATION}

In Figs. 4 and 5 show the results of modeling the trajectories of electrons with energy $E=55 \mathrm{keV}$ in a gradient magnetic field, performed under the initial condition of $z_{0}=0 \mathrm{~mm}$ for two different polar angles of entry $r_{0}^{\prime}$ into the transportation system. The following were chosen as the initial conditions: $r_{0}=21 \mathrm{~mm}$, $y_{0}=0^{\circ}, 120^{\circ}$ and $240^{\circ}$. Further

$$
\left.q_{z}^{\prime}\right|_{0}=\left.\frac{1}{\mu} \sqrt{\frac{2 E}{E_{0}},} \quad q_{\theta}^{\prime}\right|_{0}=r_{0}^{2} f\left(z_{0}\right)
$$

( $E_{0}=511 \mathrm{keV}$ is electron rest energy).

The calculation results in Figs. 4 and 5 are given for the cases of $r_{0}^{\prime}=-0.001$ and $r_{0}^{\prime}=-0.010$ radians (the "minus" sign means that the particle at the start flies in, approaching along the radius to the axis of the system).

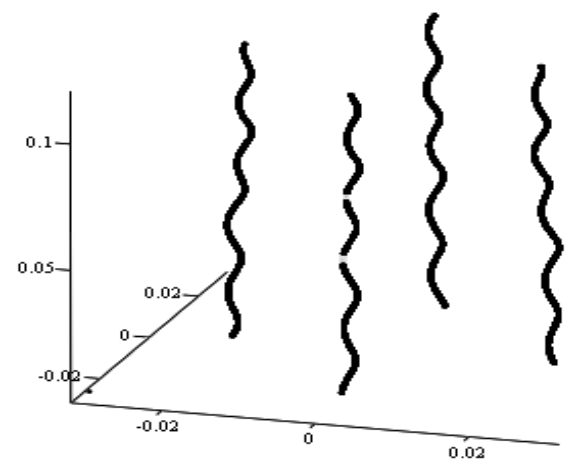

Fig. 4. Evolution of trajectories of 4 electrons. Parameters: $z_{0}=0 \mathrm{~m} ; r_{0}=21 \mathrm{~mm} ; r_{0}^{\prime}=-0.001$

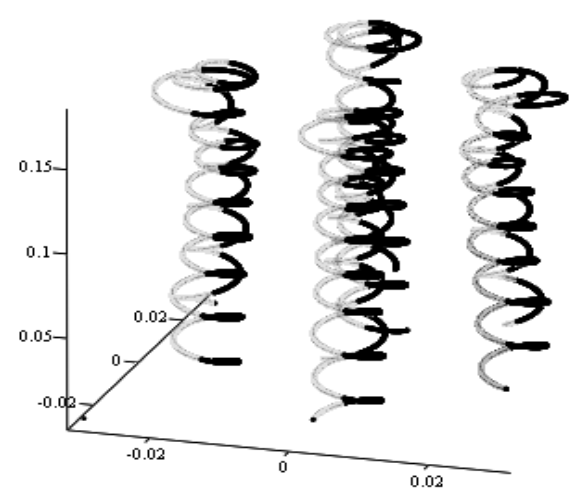

Fig. 5. Evolution of trajectories of 4 electrons. Parameters: $z_{0}=0 \mathrm{~m}, r_{0}=21 \mathrm{~mm}, r_{0}^{\prime}=-0.010$

It can be seen that at $r_{0}^{\prime}=-0.010$ in the trajectories, oscillations become more pronounced in the plane perpendicular to the $z$ axis. In addition, the particles are reflected in the gradient region of the magnetic field.

In Fig. 6 shows examples of electron trajectories for three selected entry angles $r_{0}^{\prime}$. It can be seen that an increase (in absolute value) in the entry angle leads to a significant rearrangement of the trajectory type. It is a helical line, the axis of which is one of the field lines, and the radius $\rho$ is $\rho=p c r_{0}^{\prime} / e_{0} H$ [3], where $p$ is the momentum of the particle. Perturbations of the trajectory take place in the region of the large field gradient, which is due to the large radius $r_{0}$ at the start. 
A series of trajectory dependencies is shown in Figs. 7-9. In Fig. 7 shows an example of electron trajectories for an entry angle of 0.0. They show the start point with a rectangle, and the finish point with a triangle. It can be seen that, in this case, the particle moves mainly in a straight line. Trajectory disturbances take place in the region of a large field gradient.

In Fig. 8 for those cases of the entry angle, the dependences of the current longitudinal coordinate $z$ on the path $S$ traveled by the electron along its trajectory are shown. It can be seen that starting from $r_{0}^{\prime}=-0.01$ the trajectory deviates from an almost straight line, and at $r_{0}^{\prime}=-0.02$ a reversal already takes place, followed by movement back to the cathode region.

Phase maps of $(z, r)$ trajectories are shown in Fig. 9. In the case of $r_{0}^{\prime}=-0.02$, it can be seen that the longitudinal step of the transverse oscillations decreases on the trajectory as it approaches the gradient region of the magnetic field. Further, the particle vibrates at the limit- ing return point, at which the derivative $d z / d S$ of the longitudinal coordinate $z$ vanishes. Then the electron, experiencing, as before, transverse vibrations, moves back. This motion of electrons can be compared with an optical model of the passage of light rays in a medium with the gradient refractive index depending on the radius. Figs. 8 and 9 , it follows that there are gun operation modes in which the particle experiences the "bottleneck" effect [3] and completes its movement by returning to the cathode region.

Further, the particle vibrates at the limiting return point. In it, the derivative $d z / d S$ of the longitudinal coordinate $z$ vanishes. Then the electron, continuing to experience, as before, transverse vibrations, moves backward.

The given trajectories of electrons can be compared with the model of the transmission of light rays in the medium with the gradient refractive index depending on the radius.
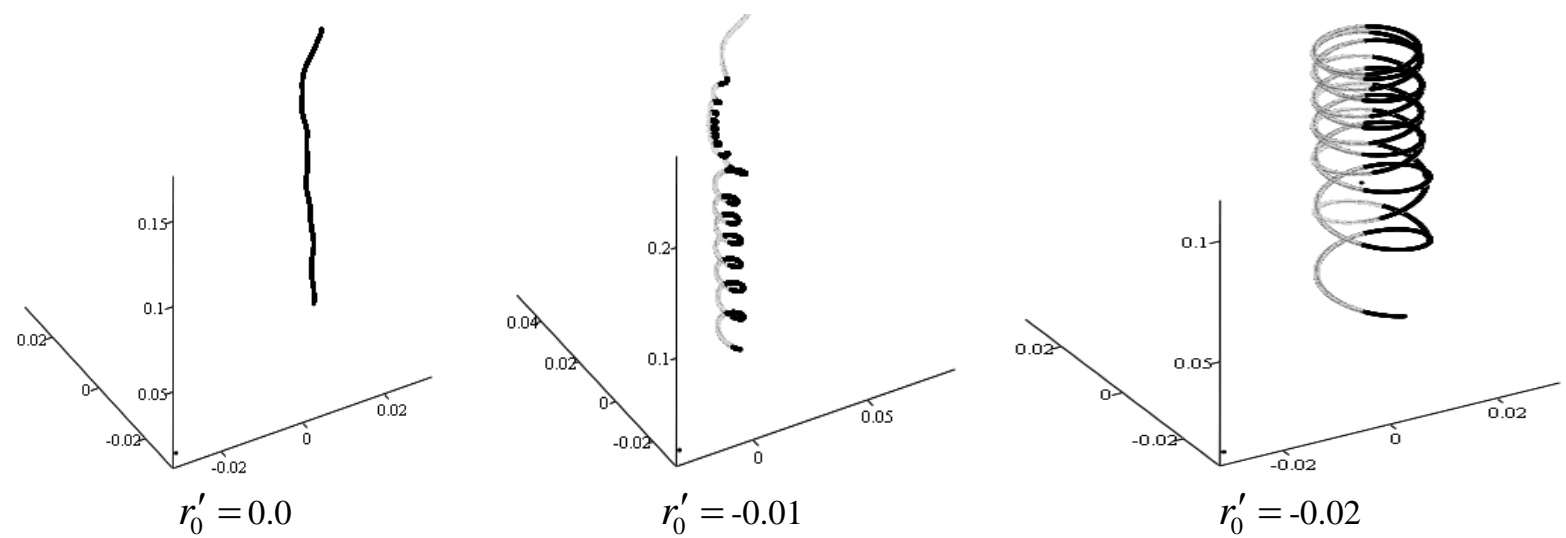

Fig. 6. The trajectory of an electron in a gradient magnetic field (the axis $z$ of the system is directed upward)
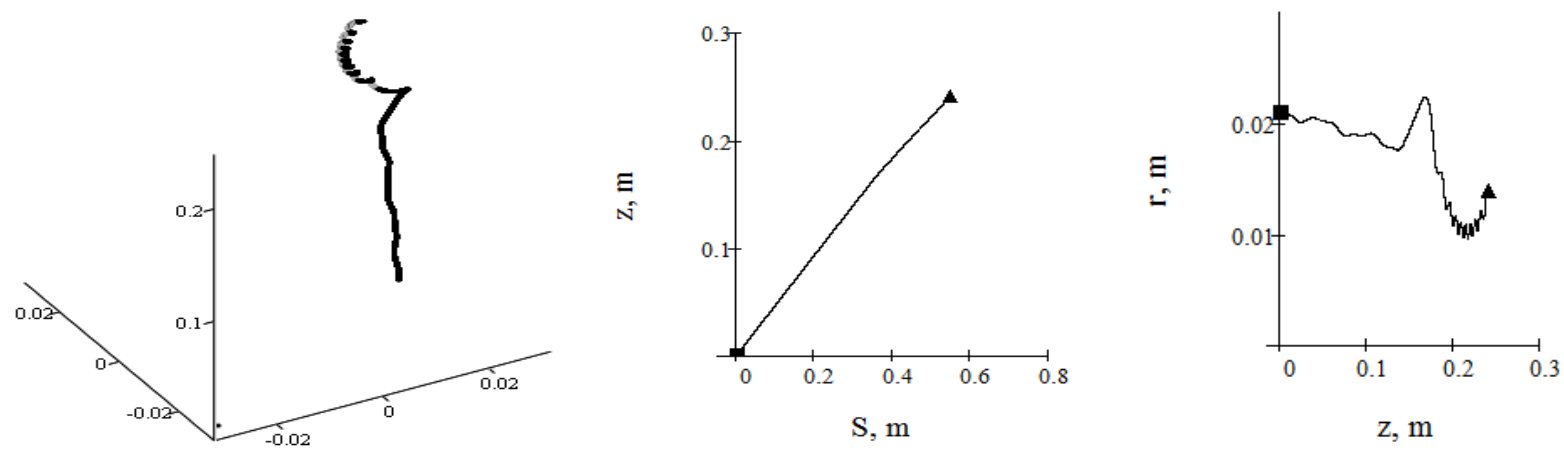

Fig. 7. Trajectory of an electron in a gradient magnetic field. Parameters: $z_{0}=0 \mathrm{~m}, r_{0}=21 \mathrm{~mm}, r_{0}^{\prime}=0.0$. On the left is the trajectory of the particle; in the middle - the dependence of $z$ on the distance traveled $S$; on the right-phase map $(z, r)$
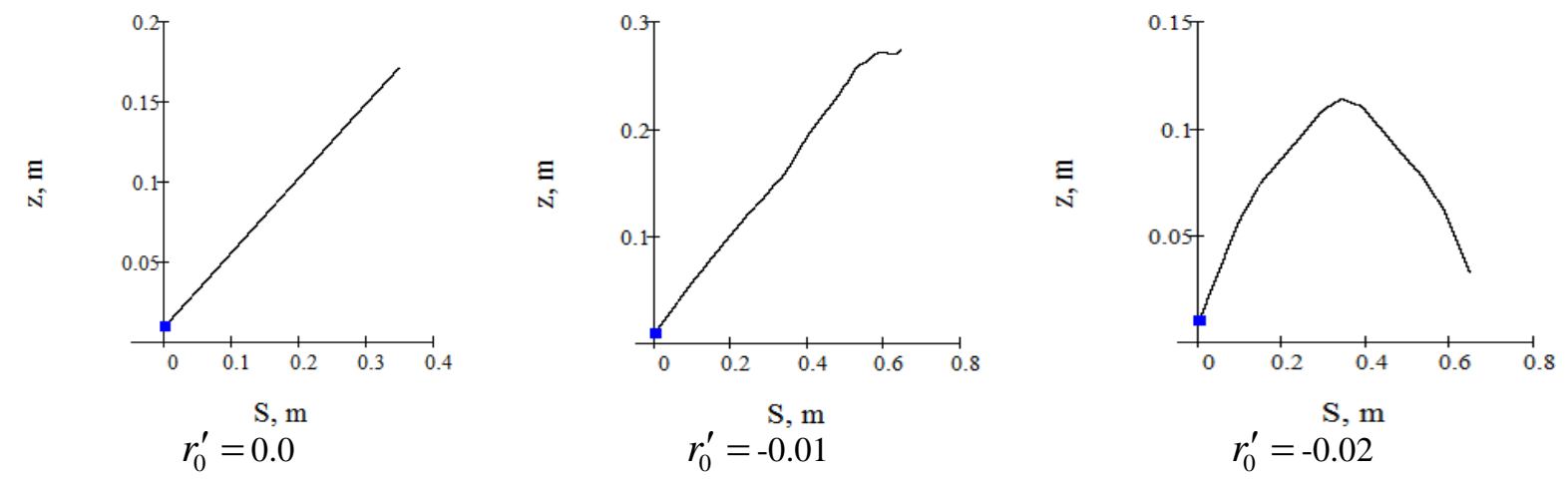

Fig. 8. Dependence of the $z$ coordinate on the path traveled by the electron $S$ (the square indicates the start) 

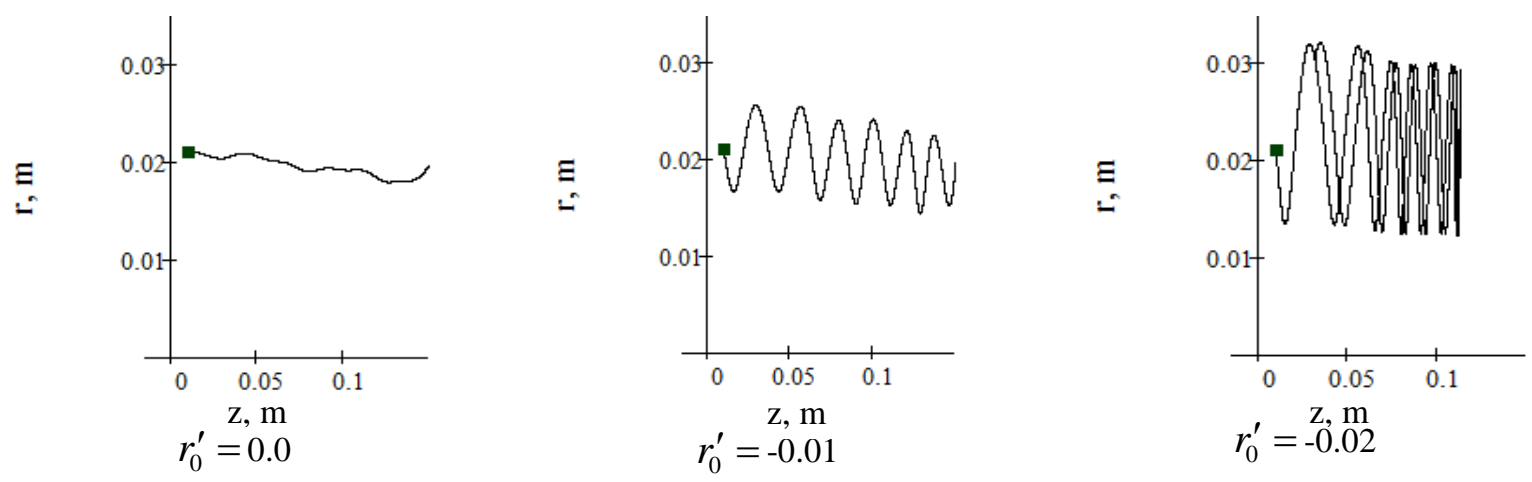

Fig. 9. Phase map $(z, r)$ (start is indicated by a square)

\section{CONCLUSIONS}

It follows from the simulation results that, for the selected initial conditions of the particles, the regulation of the initial conditions, in particular the angle of return of electrons, for a given configuration of the gradient magnetic field affects the general properties of the beam motion. When moving in the transport channel, the electron flux undergoes a transformation of the distribution density in the phase space, which is determined by the type of the gradient magnetic field. The interaction of electrons with an intense magnetic field can lead to the "bottleneck" effect of particle reflection - backward motion. For a given energy of an electron and a fixed magnetic field, the parameter that determines the reflection of a particle is the polar angle of entry relative to the axis of the magnetic field. Examples of numerical calculations are given that illustrate the bifurcation mode of the dynamics of a part when they move along the transport axis both forward to the target and back to the cathode region.

\section{REFERENCES}

1. M.I. Ayzatsky, A.N. Dovbnya, A.S. Mazmanishvili, et al. Studies on formation of the radially-directed electron beam generated by the magnetron gun with a secondary emission cathode // Problems of Atomic
Science and Technology. Series "Nuclear Physics Investigations”. 2016, № 3, p. 11-16.

2. A.S. Mazmanishvili, N.G. Reshetnyak. Electron beam transversion managemement on exit of magnetic gun by gradient magnetic field // Problems of Atomic Science and Technology. Series "Nuclear Physics Investigations”. 2019, № 6, p. 106-113.

3. L.A. Artsimovich. Controlled thermonuclear reactions. M.: "Fizmatgiz", 1963, p. 496.

4. A.S. Mazmanishvili,

N.G. Reshetnyak, O.A. Shovkoplyas. Beam and sector modes of electron beams in a cylindrical magnetic field of a magnetron gun // Journal of Nano- and Electronic Physics. 2020, v. 12, № 3, 03001 (5 pp).

5. A.S. Mazmanishvili, N.G. Reshetnyak. Transformation of the data array of the cylindrical magnetic field of the magnetron gun and the problem of the radial motion of electrons // Applied Problems of Mathematical Modeling. 2020, v. 3, № 1, p. 108-116.

6. A.N. Dovbnya, N.A. Dovbnya, A.S. Mazmanishvili, N.G. Reshetnyak. Longitudinal-radial motion of an electron beam in the solenoidal field of the secundary-emission magnetron gun // Problems of Atomic Science and Technology. Series "Nuclear Physics Investigations”. 2017, № 6, p. 96-100.

Article received 08.10.2021

\section{МОДЕЛИРОВАНИЕ КОЛЕБАТЕЛЬНЫХ И ПОВОРОТНЫХ ТРАЕКТОРИЙ ЭЛЕКТРОНОВ В ГРАДИЕНТНОМ МАГНИТНОМ ПОЛЕ МАГНЕТРОННОЙ ПУШКИ}

\section{А.С. Мазманишвили, Н.Г. Решетняк}

Рассмотрено движение электронов в цилиндрическом магнитном поле с переменной напряженностью вдоль оси. Изучено формирование пучка с энергией 55 кэВ в продольном направлении при его транспортировке в соленоидальном магнитном поле с большим градиентом. Рассмотрены бифуркационные режимы динамики частиц при их движении вдоль оси транспортировки как вперед на мишень, так и назад в прикатодную область. Получены режимы работы пушки, при которых частица испытывает эффект "бутылочного горлышка" и возвращается в прикатодную область. Показано, что при заданной энергии электрона и фиксированном магнитном поле параметром, определяющим отражение частицы, является полярный угол влета относительно оси цилиндрического магнитного поля. Приводятся результаты численного моделирования по движению электронного потока.

\section{МОДЕЛЮВАННЯ КОЛИВАЛЬНИХ І ПОВОРОТНИХ ТРАСКТОРІЙ ЕЛЕКТРОНІВ У ГРАДІСНТНОМУ МАГНІТНОМУ ПОЛІ МАГНЕТРОННОЇ ГАРМАТИ О.С. Мазманішвілі, М.Г. Решетняк}

Розглянуто рух електронів у циліндричному магнітному полі зі змінною напруженістю вздовж осі. Вивчено формування пучка з енергією 55 кеВ у поздовжньому напрямку при його транспортуванні в соленоїдальному магнітному полі з великим градієнтом. Розглянуто біфуркаційні режими динаміки часток при їх русі вздовж осі транспортування як вперед на мішень, так і назад у прикатодну область. Отримано режими роботи гармати, при яких частка відчуває ефект "пляшкового горла" і повертається в прикатодну область. Показано, що при заданій енергії електрона і фіксованому магнітному полі параметром, що визначає відображення частки, є полярний кут вльоту відносно осі циліндричного магнітного поля. Наводяться результати чисельного моделювання за рухом електронного потоку. 